\title{
High-flux isobutanol production using engineered Escherichia coli: a bioreactor study with in situ product removal
}

\author{
Antonino Baez $\cdot$ Kwang-Myung Cho • James C. Liao
}

Received: 15 October 2010 /Revised: 3 February 2011 /Accepted: 4 February 2011 / Published online: 10 March 2011

(C) The Author(s) 2011. This article is published with open access at Springerlink.com

\begin{abstract}
Promising approaches to produce higher alcohols, e.g., isobutanol, using Escherichia coli have been developed with successful results. Here, we translated the isobutanol process from shake flasks to a 1-L bioreactor in order to characterize three E. coli strains. With in situ isobutanol removal from the bioreactor using gas stripping, the engineered E. coli strain (JCL260) produced more than $50 \mathrm{~g} / \mathrm{L}$ in $72 \mathrm{~h}$. In addition, the isobutanol production by the parental strain (JCL16) and the high isobutanol-tolerant mutant (SA481) were compared with JCL260. Interestingly, we found that the isobutanoltolerant strain in fact produced worse than either JCL16 or JCL260. This result suggests that in situ product removal can properly overcome isobutanol toxicity in $E$. coli cultures. The isobutanol productivity was approximately twofold and the titer was $9 \%$ higher than $n$-butanol produced by Clostridium in a similar integrated system.
\end{abstract}

Keywords Biofuels · Isobutanol $\cdot$ E. coli $\cdot$ Gas stripping · Bioreactor

\footnotetext{
A. Baez $\cdot$ K.-M. Cho · J. C. Liao $(\bowtie)$

Department of Chemical and Biomolecular Engineering,

University of California, Los Angeles,

5531 Boelter Hall, 420 Westwood Plaza,

Los Angeles, CA 90095, USA

e-mail: liaoj@seas.ucla.edu

J. C. Liao

Institute for Genomics and Proteomics, University of California, Los Angeles,

5531 Boelter Hall, 420 Westwood Plaza,

Los Angeles, CA 90095, USA
}

\section{Introduction}

The growing need for alternative energy calls for new strategies to produce liquid fuels such as alcohols, alkanes, and fatty acid esters (or biodiesel) from renewable sources (Dellomonaco et al. 2010; Peralta-Yahya and Keasling 2010; Solomon 2010). Compared to ethanol, higher alcohols (e.g., 1-propanol, isobutanol, n-butanol, 2methyl-1-butanol, 3-methyl-1-butanol) have higher energy density and lower hygroscopicity, which make them better candidates as gasoline additives or substitutes. However, no native organisms have been identified to produce these advanced biofuels in appreciable quantities (Clomburg and Gonzalez 2010). For example, isobutanol was identified as a by-product in beer fermentation, but with a titer as low as $16 \mathrm{mg} / \mathrm{L}$ (Garcia et al. 1994). Since the feasibility of a bioprocess depends critically on the final product titer (Stephanopoulos 2007), a synthetic approach to produce higher alcohols from nonfermentative pathways in Escherichia coli was previously devised (Atsumi et al. 2008b). In addition, metabolic engineering efforts to produce these alcohols at higher titers and yields have been performed (Atsumi et al. 2008a, b; Cann and Liao 2008; Clomburg and Gonzalez 2010; Connor and Liao 2008; Jarboe et al. 2010; Shen and Liao 2008; Smith et al. 2010). This strategy uses the amino acid biosynthetic pathway and diverts its 2ketoisovalerate for isobutanol synthesis by overexpression of 2-ketoisovalerate decarboxylase (Kivd) and alcohol dehydrogenase (AdhA). Because of the ubiquity of the amino acid pathways, this strategy is compatible with many organisms and shows significant promise for industrial applications. 
In particular, Atsumi et al. (2008b) engineered an E. coli strain (JCL260) as a host for isobutanol production. Genes that code for proteins involved in by-product formation from pyruvate and acetyl-CoA were deleted in JCL260 (Table 1) with an intention to increase pyruvate availability for isobutanol synthesis. Such deletions improved the isobutanol production of JCL260 strain compared to its parental strain, JCL16, under micro-aerobic conditions in shake flasks (Atsumi et al. 2008b). Even without any process optimization, Atsumi et al. (2008b) were able to produce $22 \mathrm{~g} / \mathrm{L}$ of isobutanol in $112 \mathrm{~h}$ with a yield of $86 \%$ of the theoretical maximum.

Although this titer is $85 \%$ and $12 \%$ higher than those reported by Ezeji et al. (2003) and Qureshi and Blaschek (1999), respectively, for $n$-butanol produced by Clostridium in batch bioreactors, industrial-scale fermentation processes require higher final titers to be economically feasible. The final product titer can be limited by various factors depending on the particular production strain and bioprocess. Since isobutanol is toxic to the cell, isobutanol production from glucose may be limited by the toxicity of the final product itself. In this sense, improving the tolerance of the biocatalyst becomes a primary necessity to achieve a process with high product titers (Alper et al. 2006; Gonzalez et al. 2003; Jarboe et al. 2010; Miller and Ingram 2007; Yomano et al. 1998). It has been reported that $E$. coli was unable to grow at isobutanol concentrations $>8 \mathrm{~g} / \mathrm{L}$ (Brynildsen and Liao 2009). Even though the E. coli strain continued to produce isobutanol after it ceased to grow (Atsumi et al. 2008b), product toxicity may eventually damage the cell and limit the final titer (Rutherford et al. 2010). In this regard, Atsumi et al. (2010b) isolated and characterized an isobutanol-tolerant E. coli strain (SA481) able to grow at $8 \mathrm{~g} / \mathrm{L}$. SA481 was evolved from the high isobutanol producer strain (JCL260) by a sequential transfer method increasing isobutanol concentration every 15 transfers. The SA481 strain showed superior growth characteristics compared to the high producer (JCL260) strain when they both were cultivated at 6 and $8 \mathrm{~g} / \mathrm{L}$ of isobutanol. Compared with the control condition, specific growth rate for JCL260 decreased by $35 \%$ and $74 \%$ at 6 and $8 \mathrm{~g} / \mathrm{L}$ of isobutanol (calculated from data showed by Atsumi et al. 2010b), respectively, while SA481 growth was not affected at $6 \mathrm{~g} / \mathrm{L}$ of isobutanol and decreased just $13 \%$ at $8 \mathrm{~g} / \mathrm{L}$. Interestingly, Atsumi et al. (2010b) also showed that SA481 did not produce more isobutanol than JCL260 under normal conditions. However, the experiments were performed in shake flasks. Accordingly, the performance of SA481 harboring pSA65/pSA69 for isobutanol production in bioreactors will be evaluated in this work.

The other approach to solve the cytotoxicity problem and its detrimental effect on the final titer from a bioprocess perspective is the in situ product removal. Several in situ solvent recovery strategies have been developed for $n$-butanol fermentation (Groot et al. 1992; Nielsen and Prather 2009; Roffler et al. 1987; Qureshi et al. 2005). Since gas stripping is a simple and efficient way to recover the solvent from the fermentation broth (Inokuma et al. 2010; Lee et al. 2008), in the present work, gas stripping integrated with fermentation was used to compare the isobutanol production by the high producer (JCL260), isobutanol-tolerant (SA481), and the parental (JCL16) strains carrying pSA65 and pSA69 plasmids. We hypothesize that if isobutanol could be removed from the fermentation broth, the production can be extended significantly and the final titer will surpass the $22 \mathrm{~g} / \mathrm{L}$ obtained previously in flask cultures.

\section{Materials and methods}

Strains, plasmids, and pre-culture

Strains and plasmids used are shown in Table 1. A single colony of freshly transformed cells was inoculated into a 250-mL screw-cap flask containing $25 \mathrm{~mL}$ of Luria-Bertani media with antibiotics $(0.05 \mathrm{~g} / \mathrm{L}$ kanamycin and $0.1 \mathrm{~g} / \mathrm{L}$ ampicillin). Overnight pre-culture was performed at $37^{\circ} \mathrm{C}$ on a rotary shaker $(250 \mathrm{rpm})$.

Table 1 Strains and plasmids used in this study

Relative characteristics

BW25113/F' $\left[\operatorname{traD} 36\right.$, proAB ${ }^{+}$, lacl $\left.^{\mathrm{q}} \mathrm{Z} \Delta \mathrm{M} 15\right]$

Strains

JCL16

JCL260

SA481

JCL260 $\triangle$ poxB

Plasmids

pSA65

pSA69
Same as JCL16 but with $\triangle a d h E, \Delta f r d B C, \Delta f n r, \Delta l d h A, \Delta p t a, \Delta p f l B$

Isobutanol-tolerant strain, JCL260 derivative

Same as JCL260 but with $\Delta$ poxB

ColE1 ori; $\mathrm{Amp}^{\mathrm{R}} ; P_{L} \mathrm{lacO}_{1}$ : kivd-adhA (Lactococcus lactis)

$\mathrm{P} 15$ ori; $\mathrm{Kan}^{\mathrm{R}} ; P_{L} \mathrm{lacO}_{1}$ : alsS (Bacillus subtilis)-ilvCD
Reference

Atsumi et al. (2008a)

Atsumi et al. (2008a)

Atsumi et al. (2010b)

Laboratory collection

Atsumi et al. (2010a)

Atsumi et al. (2008b) 
Culture media for bioreactor fermentations

Culture media for bioreactor cultures contained the following composition, in grams per liter: glucose, 55; $\left(\mathrm{NH}_{4}\right)_{2} \mathrm{SO}_{4}, 3$; $\mathrm{K}_{2} \mathrm{HPO}_{4}, 14.6 ; \mathrm{KH}_{2} \mathrm{PO}_{4}$, 4; sodium citrate, 2.2; yeast extract, 25; $\mathrm{MgSO}_{4} \cdot 7 \mathrm{H}_{2} \mathrm{O}, 1.25$; ampicillin, 0.1; kanamycin, 0.05; and $1 \mathrm{~mL} / \mathrm{L}$ of trace metal solution. Trace metal solution contained, in grams per liter: EDTA, 14.1; $\mathrm{CoCl}_{2} \cdot 6 \mathrm{H}_{2} \mathrm{O}, 2.5$; $\mathrm{MnCl}_{2} \cdot 4 \mathrm{H}_{2} \mathrm{O}, 15 ; \mathrm{CuCl}_{2} .2 \mathrm{H}_{2} \mathrm{O}, 1.5 ; \mathrm{H}_{3} \mathrm{BO}_{3}, 3$; $\mathrm{Na}_{2} \mathrm{MoO}_{4} \cdot 2 \mathrm{H}_{2} \mathrm{O}, 2.1 ; \mathrm{Zn}\left(\mathrm{CH}_{3} \mathrm{COO}\right)_{2} \cdot 2 \mathrm{H}_{2} \mathrm{O}, 33.8 ; \mathrm{Fe}$ (III) citrate 100.8. The feeding solution contained, in grams per liter: glucose, 500; $\mathrm{MgSO}_{4} \cdot 7 \mathrm{H}_{2} \mathrm{O}, 1.25$; ampicillin, 0.1; kanamycin, 0.05, $0.1 \mathrm{mM}$ of isopropyl-B-D-thio-galactoside (IPTG); and $1 \mathrm{~mL} / \mathrm{L}$ of trace elements.

Bioreactor culture conditions

Cultures of E. coli were performed in 1-L stirred tank bioreactor (Applikon Biotechnology, Schiedam, the Netherlands) using a working volume of $0.35 \mathrm{~L}$. The bioreactor was inoculated with $2 \%$ of overnight preculture and the cells grown at $37^{\circ} \mathrm{C}$. After $2 \mathrm{~h}, 0.1 \mathrm{mM}$ IPTG was added and the temperature was decreased to $30^{\circ} \mathrm{C}$ to start isobutanol production. The induction time represents the beginning of fermentation described in Fig. 2. Isobutanol production was tested at two temperatures, $30^{\circ} \mathrm{C}$ and $37^{\circ} \mathrm{C}$, for JCL260. The $\mathrm{pH}$ was controlled at 6.8 by automatic addition of $2 \mathrm{M} \mathrm{NaOH}$ solution. Dissolved oxygen (DO) was maintained above $20 \%$ with respect to air saturation by raising stirrer speed (from 200 to $600 \mathrm{rpm}$ ). Air was bubbled in the bioreactor with two goals: (1) provide oxygen and (2) in situ isobutanol stripping out. Air flow rate was maintained at $0.5 \mathrm{vvm}$ the first $3 \mathrm{~h}$ of isobutanol production and then was increased to $1.2 \mathrm{vvm}$ in order to remove isobutanol from the culture broth. The evaporated isobutanol was condensed using two Graham condensers connected in series (Fig. 1). The exhaust gases from the fermentor were bubbled in a trap (picker B containing $800 \mathrm{~mL}$ of water; Fig. 1) cooled with ice and then circulated through condenser 1 (L $300 \mathrm{~mm}$ and cooling coil surface area $400 \mathrm{~cm}^{2}$; Fig. 1) maintained at $4{ }^{\circ} \mathrm{C}$. After that, gas continued circulating through a second equal loop (D receiver and condenser 2; Fig. 1). Fermentation was allowed to proceed in batch mode until entry into the stationary phase (between 9 and $10 \mathrm{~h}$ ), and then an intermittent manual feeding was started to avoid glucose depletion. Fermentation samples were collected to determinate growth, isobutanol production, and organic acid and glucose concentrations.

Analytical methods

Cell growth was followed by optical density measurements at $600 \mathrm{~nm}$ and converted to dry cell weight concentration

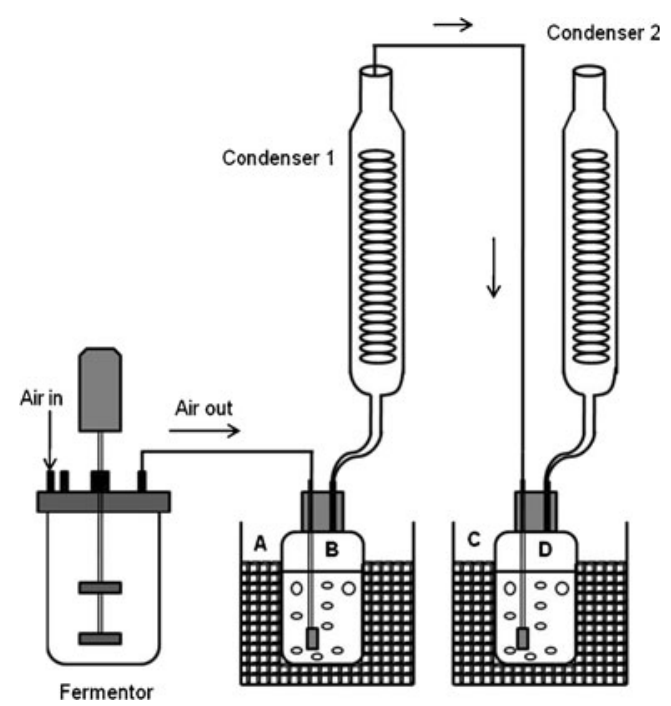

Fig. 1 Schematic diagram of fermentation/gas stripping process for isobutanol production by $E$. coli. $A$ and $C$ are ice containers to cool recipients $B$ and $D . B$ and $D$ are receivers containing $0.8 \mathrm{~L}$ of water where the evaporated isobutanol was collected

by calibration plots of samples dried to constant weight in an oven at $80^{\circ} \mathrm{C}$. Glucose concentration was determined with YSI biochemical analyzer (YSI Instruments, Yellow Springs, OH, USA). Isobutanol concentration was quantified by a gas chromatograph (GC) model 6850 (Agilent Technologies, Santa Clara, CA, USA) equipped with flame ionization detector 6850 series (Agilent Technologies). A 30-m, 0.32-mm i.d., 0.25- $\mu \mathrm{m}$ DB-FFAP capillary column was used. GC oven temperature was initially held at $85^{\circ} \mathrm{C}$ for $3 \mathrm{~min}$ and raised with a gradient $45^{\circ} \mathrm{C} / \mathrm{min}$ until $225^{\circ} \mathrm{C}$ and held for $3 \mathrm{~min}$. Helium at $1.7 \mathrm{~mL} / \mathrm{min}$ was used as the carrier gas with 9.52-psi inlet pressure. A volume of $1 \mu \mathrm{L}$ supernatant of the culture broth was injected using 1-pentanol as internal standard. Acetate concentration was determined by high-pressure liquid chromatography (Agilent Technologies) with an Aminex HPX-87H column (Bio-Rad Laboratories, Hercules, CA, USA) maintained at $35^{\circ} \mathrm{C}$. A mobile phase of $5 \mathrm{mM} \mathrm{H}_{2} \mathrm{SO}_{4}$ was used at $0.6 \mathrm{~mL} / \mathrm{min}$.

Preparation of cell-free extracts and enzyme activity assays

Cells were harvested by centrifugation at $10,000 \times g$ for $10 \mathrm{~min}$ at $4^{\circ} \mathrm{C}$ from bioreactor cultures, washed twice with $50 \mathrm{mM}$ potassium phosphate buffer $(\mathrm{pH} 7.0)$, and stored frozen at $-80^{\circ} \mathrm{C}$. Frozen cells were suspended in the same washing buffer, blended with glass beads, and disrupted in series $4 \times 1 \mathrm{~min}$. Crude extract was centrifuged at $10,000 \times \mathrm{g}$ at $4^{\circ} \mathrm{C}$ for $30 \mathrm{~min}$ and the supernatant used for enzyme assays. The concentration of the protein preparation was determined by the Bradford method. Acetolactate synthase (AlsS) and dihydroxy-acid dehydratase (IlvD) assays were performed as described by Atsumi et al. 

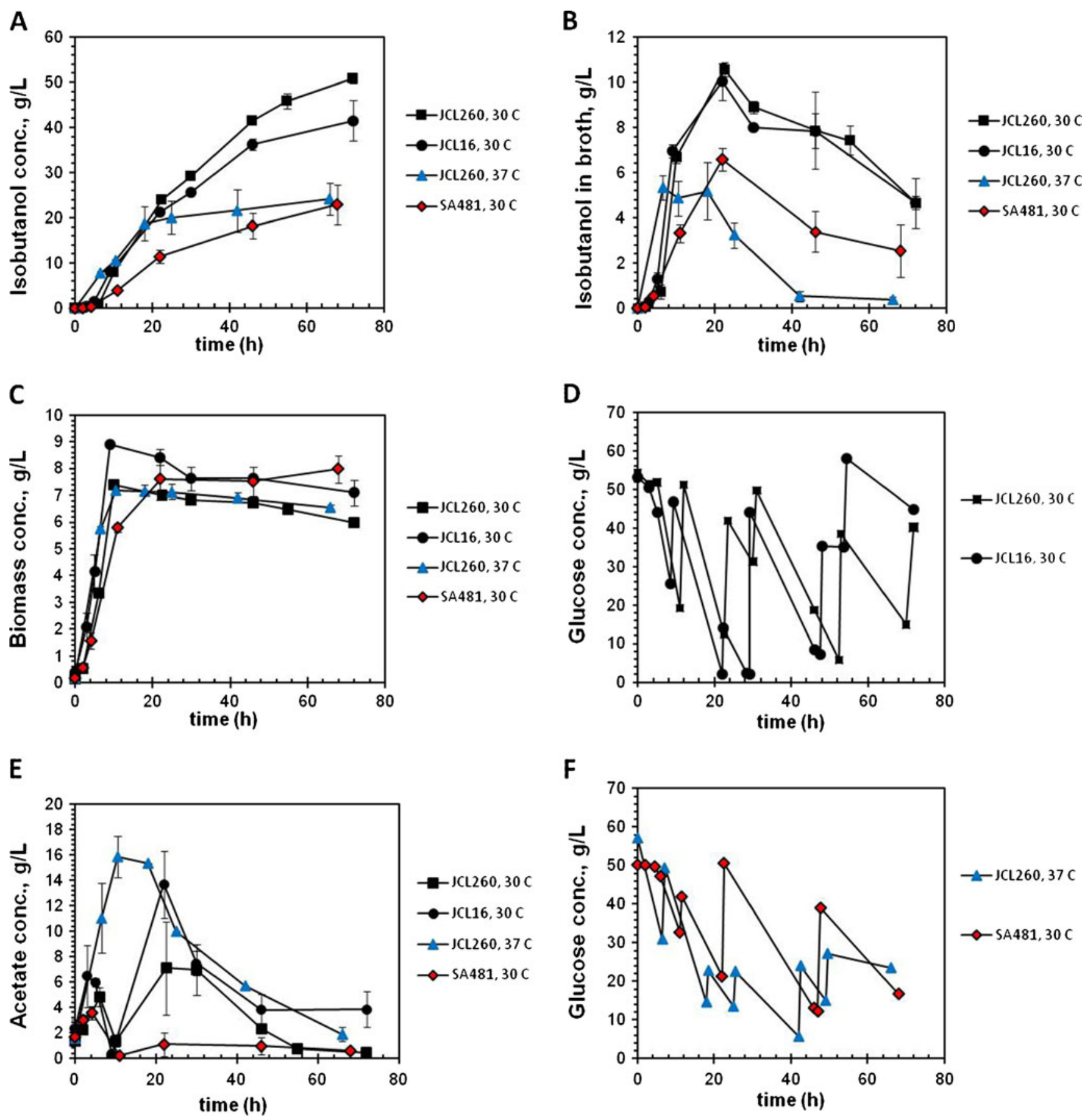

Fig. 2 Typical kinetics of isobutanol production by JCL260, JCL16, and SA481 strains harboring pSA65/pSA69. a Total isobutanol production (calculated as sum of isobutanol quantities determined in receivers $\mathrm{B}, \mathrm{D}$, and broth culture considering a working volume of $0.35 \mathrm{~L}$ ). b Isobutanol concentration in fermentation broth. c Cell growth. d, f Glucose consumption. e Acetate production. High

$\mathbf{F}$

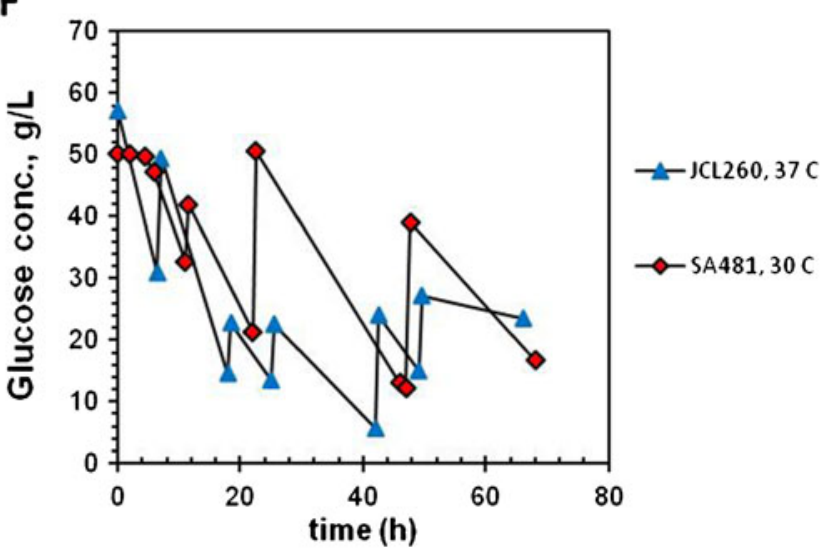

isobutanol producer (JCL260) at $30^{\circ} \mathrm{C}$ (closed squares), parental (JCL16) at $30^{\circ} \mathrm{C}$ (closed circle), high isobutanol producer (JCL260) at $37^{\circ} \mathrm{C}$ (closed triangles) and high isobutanol-tolerant strain (closed diamond). Error bars correspond to the difference between duplicate cultures $(\mathbf{a}-\mathbf{c}, \mathbf{e})$. For clarity, one set of data has been plotted in $\mathbf{d}$ and $\mathbf{f}$

(2009). KivD activity was assayed by measuring NADPH oxidation at $340 \mathrm{~nm}$ in $50 \mathrm{mM}$ phosphate buffer ( $\mathrm{pH} 7.0$ ), $1 \mathrm{mM} \mathrm{MgCl} 2,1.5 \mathrm{mM}$ TTP, $0.1 \mu \mathrm{M}$ alcohol dehydrogenase (ADH6) NADPH-dependent, $0.2 \mathrm{mM} \mathrm{NADPH}$, and $30 \mathrm{mM}$ KIV. Since NADPH oxidation was proportional to

isobutiraldehyde production, it was possible to determine KivD activity. Alcohol dehydrogenase activity was detected by measuring NADH oxidation at $340 \mathrm{~nm}$ in $100 \mathrm{mM}$ MOPS, pH 7.0, 0.2 mM NADH, and $25 \mathrm{mM}$ isobutaraldehyde. 


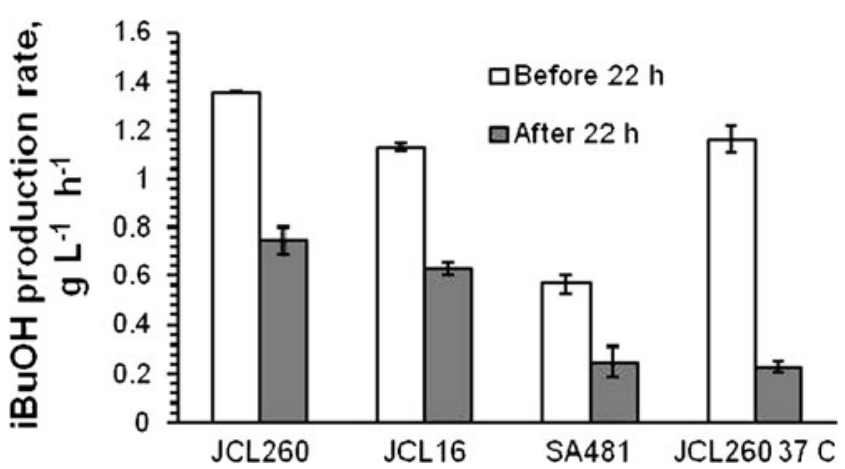

Fig. 3 Volumetric isobutanol production rate calculated as slope from time profile of isobutanol production before and after $22 \mathrm{~h}$ for all cultures, except for JCL2 60 at $37^{\circ} \mathrm{C}$ where it was determined before and after 16 h. Error bars represent the difference between duplicate cultures

\section{Results}

Comparison of high isobutanol producer (JCL260), high isobutanol-tolerant (SA481), and parental (JCL16) strains at $30^{\circ} \mathrm{C}$

In the present work, bioreactor cultures of JCL260 were performed by controlling DO above $20 \%, \mathrm{pH}$ at 6.8 , and temperature at $30^{\circ} \mathrm{C}$ and were compared with JCL16 and SA481. A high aeration rate (1.2 vvm) was used for in situ isobutanol recovery. Typical kinetics of isobutanol produc- tion, cell growth, glucose consumption, and acetate production are shown in Fig. 2. Isobutanol concentration plotted in Fig. 2a represents the total isobutanol produced by the culture quantified from receivers B, D (Fig. 1), and fermentation broth. The total isobutanol concentration was calculated as a sum of isobutanol quantities determined in receivers $\mathrm{B}, \mathrm{D}$, and broth culture considering a working volume of $0.35 \mathrm{~L}$. Note that we condensed isobutanol into water again for easy quantitation. One could directly condense isobutanol without redissolving into water.

Isobutanol production continued even after cell growth was stopped (Fig. 2a, c). In fact, around $80 \%$ of total isobutanol accumulated by JCL260 cultivated at $30^{\circ} \mathrm{C}$ was produced after the growth phase. Such behavior was similar to that reported by Atsumi et al. (2008b), but 2.3-fold higher. The high isobutanol producer strain (JCL260) accumulated $50.8 \pm 1.1 \mathrm{~g} / \mathrm{L}$ of isobutanol in $72 \mathrm{~h}$ and the parental (JCL16) $41.4 \pm 4.5 \mathrm{~g} / \mathrm{L}$ in the same time (Fig. 2a). Surprisingly, the high isobutanol-tolerant strain (SA481) produced only $23 \pm 4.4 \mathrm{~g} / \mathrm{L}$ of total isobutanol in $68 \mathrm{~h}$. After $22 \mathrm{~h}$, the maximum isobutanol concentration in the fermentation broth for JCL260 and JCL16 was around $11 \mathrm{~g} / \mathrm{L}$ and for SA481 around $6.5 \mathrm{~g} / \mathrm{L}$ (Fig. 2b). The maximum cell concentrations for JCL16, SA481, and JCL260 were $8.4 \pm 0.3,7.6 \pm 0.7$, and $6.7 \pm 0.16 \mathrm{~g} / \mathrm{L}$, respectively (Fig. 2c).

Since the aeration rate, temperature, and pressure (hence the desorption rate) were maintained constant and at the
Fig. 4 Time profile of acetate production by JCL260 PoxB $^{-}$mutant and high isobutanol producer (JCL260) strains harboring $\mathrm{pSA} 65 / \mathrm{pSA} 69$ plasmids cultivated in shake flasks containing $25 \mathrm{~mL}$ of medium. Data shown are the results of three independent fermentations
A
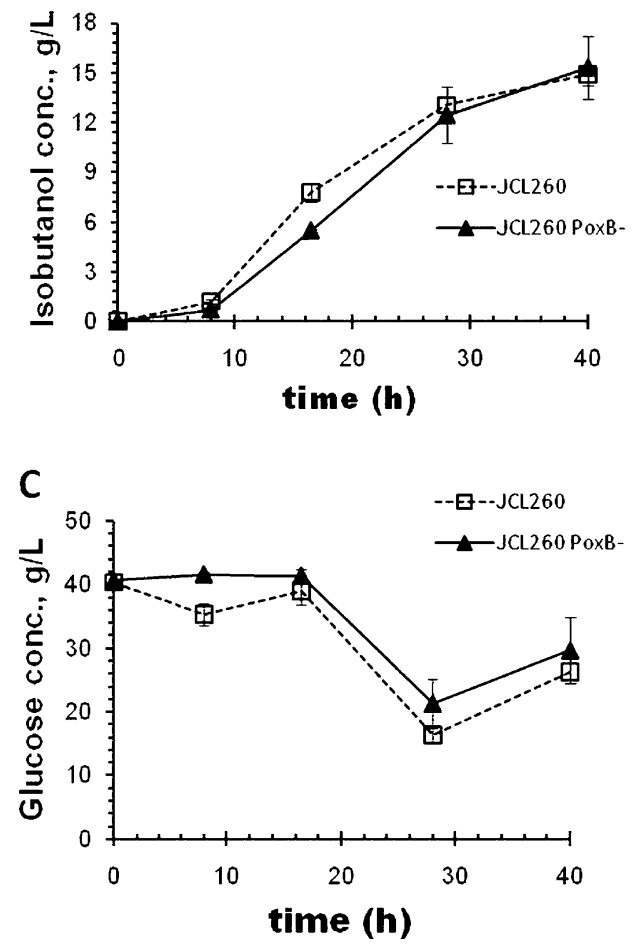

B
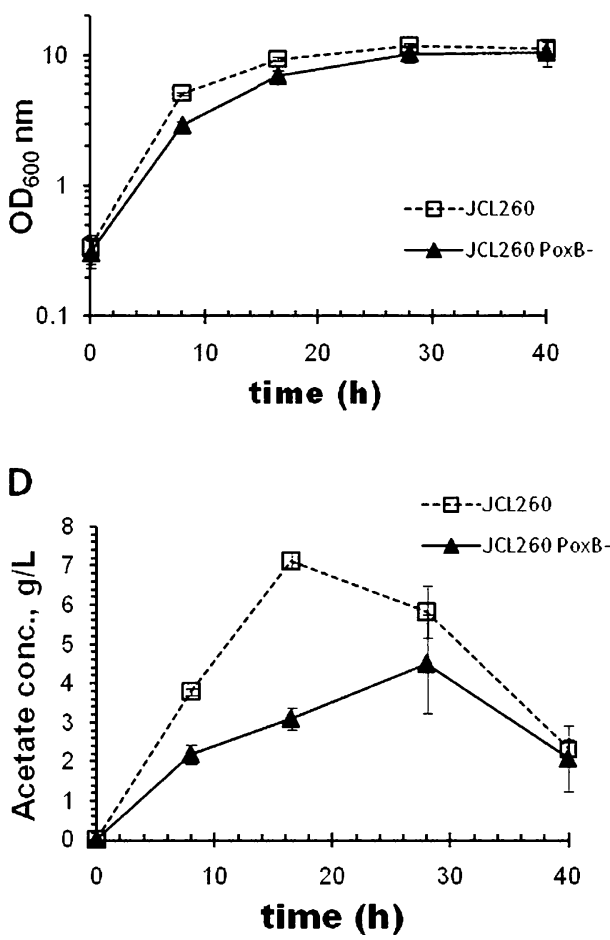
Fig. 5 Time profile of acetate production by JCL260 PoxB ${ }^{-}$mutant and high isobutanol producer (JCL260) carrying pSA65/pSA69 in bioreactor cultures. Data shown are duplicated and single fermentation for JCL260 and JCL260 PoxB ${ }^{-}$, respectively
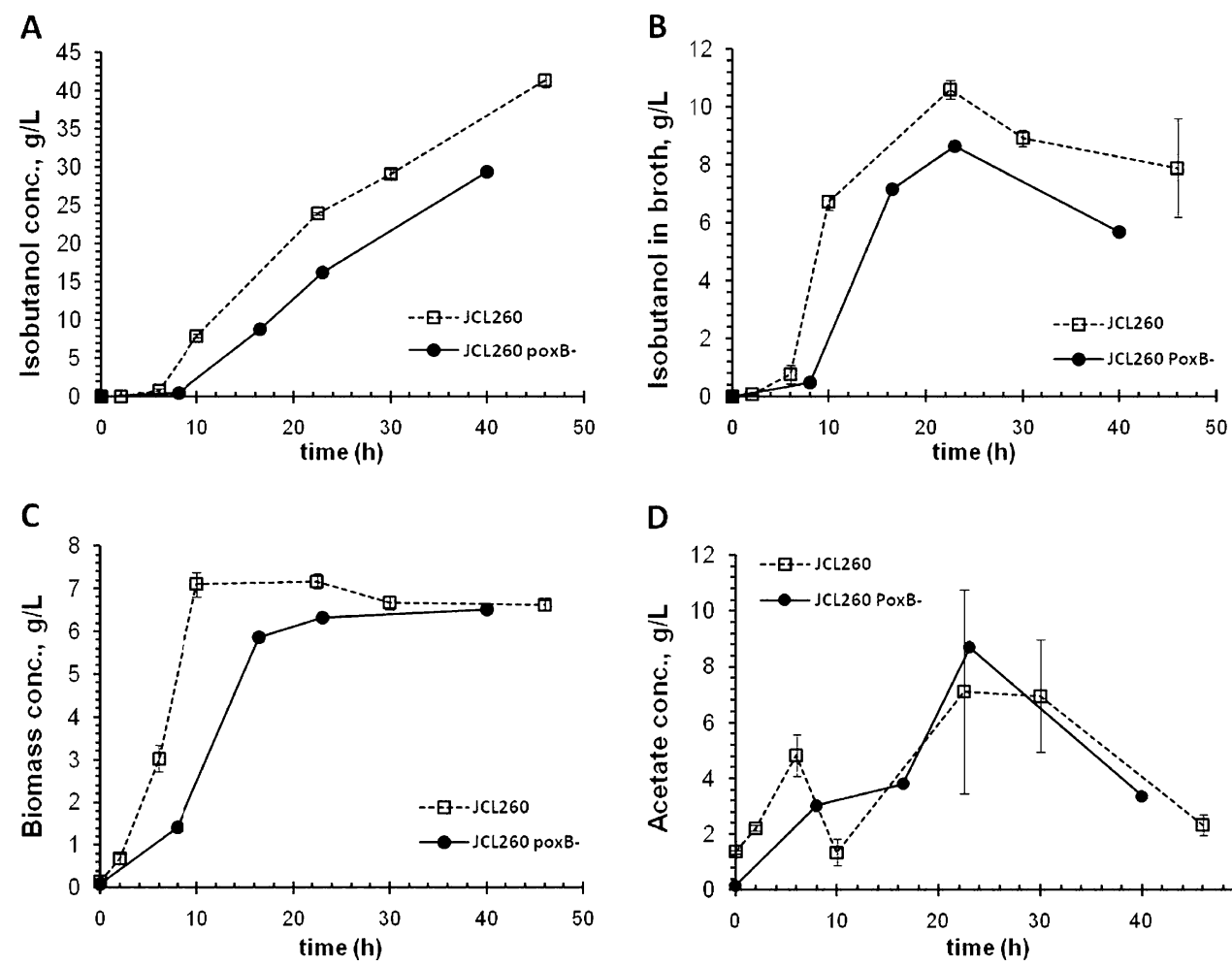

D

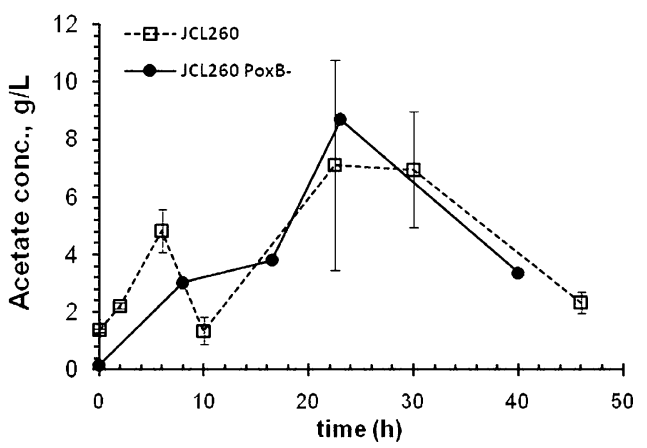

same level for all cultures, the differences in the isobutanol concentration accumulated in the fermentation broth can be attributed to differences in the isobutanol production rate (Figs. 2b and 3). Isobutanol production rate did not remain constant and decreased progressively after the growth phase. As inferred from Fig. $2 b$, the isobutanol production rate decreased dramatically after $22 \mathrm{~h}$, for JCL260 and JCL16 cultivated at $30^{\circ} \mathrm{C}$, suggesting that some events (e.g., loss of enzyme activities or substrate depletion) took place at that time. Accordingly, volumetric isobutanol production rate was calculated before and after $22 \mathrm{~h}$ of culture, being higher before $22 \mathrm{~h}$ (Fig. 3). JCL260 and JCL16 reached the maximum cell density around $10 \mathrm{~h}$ and SA481 at $22 \mathrm{~h}$. The cell density of SA481 was constant until the end of culture, while JCL260 and JCL16 presented a slight decrease (Fig. 2c), presumably due to the differences in isobutanol tolerance. The cell growth stopped around $10 \mathrm{~h}$ (JCL260 and JCL16) and cells did not grow even after feeding. Initial glucose concentration was approximately $55 \mathrm{~g} / \mathrm{L}$ and maintained above $2 \mathrm{~g} / \mathrm{L}$ in all cultures by intermittent additions of $500 \mathrm{~g} / \mathrm{L}$ glucose solution (Fig. 2d). Since isobutanol production mainly comes from glucose carbon and not from yeast extract (Atsumi et al. 2008b), glucose depletion was avoided because long starvation times (more than $1 \mathrm{~h}$ ) diminished the isobutanol production (data not shown). Completely aerobic conditions were maintained in all cultures, and lactate, formate, and ethanol were not detected in the broth culture.
Acetate was the major by-product detected, which is a well-known result of carbon imbalance during overfeeding, known as overflow metabolism (Farmer and Liao 1997; Wolfe 2005; Wong et al. 2008). Maximum acetate concentrations reached during the growth phase (first $10 \mathrm{~h}$; Fig. 2e) were $4.8 \pm 0.8,7.5 \pm 2.6$, and $3.5 \pm 0.5 \mathrm{~g} / \mathrm{L}$ for JCL260, JCL16, and SA481, respectively. JCL16 and JCL260 accumulated $13.7 \pm 2.6$ and $7.1 \pm 3.6 \mathrm{~g} / \mathrm{L}$ of acetate at $22 \mathrm{~h}$, respectively. Although JCL260 accumulated less acetate than parental (JCL16), pta deletion in JCL260 was not enough to avoid acetate accumulation (Fig. 2e). Since the strain still had the PoxB path to acetate production, its contribution was tested by deleting the poxB gene (Fig. 4). Thus, JCL260 and JCL260 $\Delta$ poxB mutant were compared in flask cultures. Isobutanol production and maximum cell density were similar in both strains (Fig. 4a, b). Glucose consumption for JCL260 was just slightly higher than JCL260 $\triangle$ poxB. However, acetate accumulated by JCL260 at $16.5 \mathrm{~h}$ was twofold higher than the $\Delta$ poxB strain. This result suggested that poxB did contribute to the acetate accumulation. Additionally, both strains were also tested in bioreactor cultures with integrated stripping out system, and the results are shown in Fig. 5. Growth and isobutanol time profile were different for JCL260 and JCL260 $\Delta$ poxB mutant (Fig. 5a-c). Unexpectedly, JCL260 $\Delta$ poxB did not grow as well as JCL260 and produced less isobutanol, while acetate accumulation was similar for both strains. Deletion of pta and poxB (JCL260 $\Delta$ poxB strain) did not 

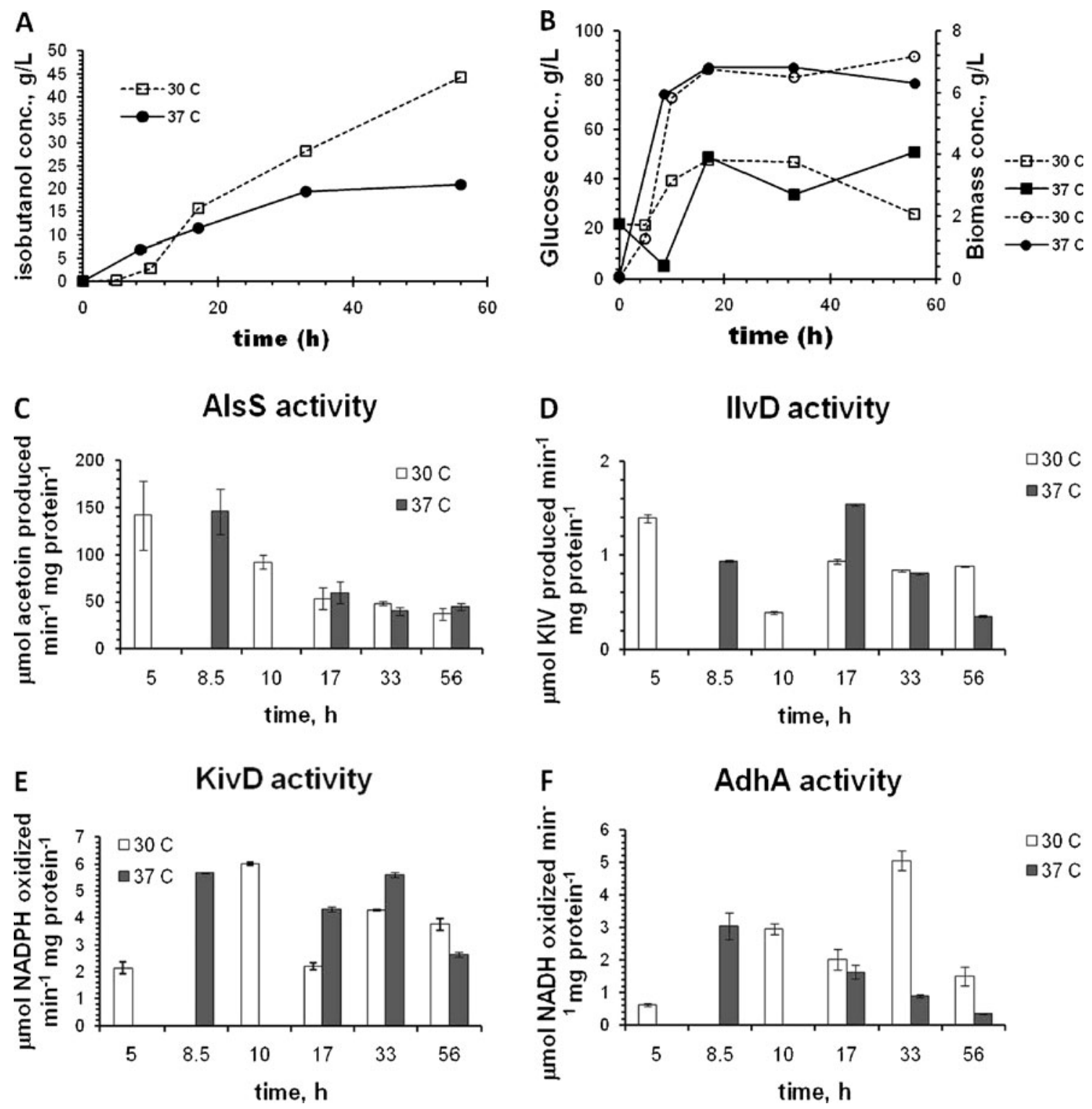

Fig. 6 Enzyme activity of isobutanol pathway for JCL260 carrying pSA65/pSA69 plasmids in bioreactor cultures at $30^{\circ} \mathrm{C}$ (open symbols) and $37^{\circ} \mathrm{C}$ (closed symbols). a Total isobutanol production calculated as sum of isobutanol concentrations from receivers B, D (Fig. 1), and broth culture considering a working volume of $0.35 \mathrm{~L}$. b Time profile

eliminate acetate accumulation, but even a triple mutant $(\Delta a c k \Delta p t a \Delta p o x \mathrm{~B})$ was not enough to eliminate acetate accumulation during aerobic fermentation (Chang et al. 1999; Phue et al. 2010), suggesting that acetate might also come from other pathways.

Time profile of high isobutanol producer strain (JCL260) at $30^{\circ} \mathrm{C}$ and $37^{\circ} \mathrm{C}$

Since vapor pressure increases with temperature, higher temperature should increase the gas stripping rate, and

of glucose concentration and cell growth. c Acetolactate synthase $(A l s S)$ activity. d Dihydroxy-acid dehydratase activity. e 2Ketoisovalerate decarboxylase (KivD) activity. f Alcohol dehydrogenase $(A d h A)$ activity. Error bars indicate the difference between duplicate assays

consequently, isobutanol concentration in the fermentation broth should be lower. Accordingly, the isobutanol production by JCL260 was evaluated at $37^{\circ} \mathrm{C}$ and compared with the production at $30^{\circ} \mathrm{C}$ (Fig. 2a). Unfortunately, the maximum isobutanol concentration was twofold lower at $37^{\circ} \mathrm{C}$ compared with that at $30^{\circ} \mathrm{C}$. The isobutanol concentration in the fermentation broth reached $5.3 \mathrm{~g} / \mathrm{L}$ and decreased until $0.4 \mathrm{~g} / \mathrm{L}$ at the end of culture (Fig. 2b). The maximum biomass concentration $(7.2 \mathrm{~g} / \mathrm{L})$ was practically the same for both temperatures (Fig. 2c). Glucose depletion was avoided by intermittent feeding in all cultures (Fig. 2d). Acetate produc- 


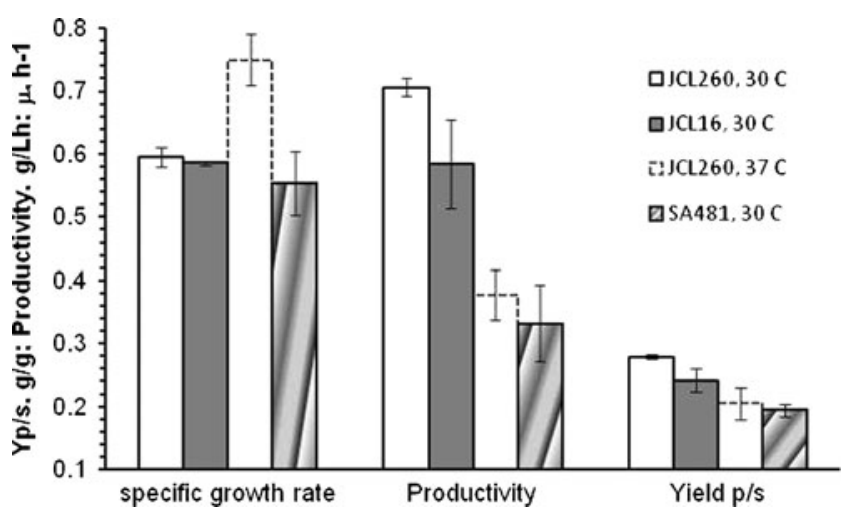

Fig. 7 Comparison of specific growth rate ( $\mu$, liters per hour), volumetric productivity (grams per liter per hour) and product yield on glucose $\left(Y_{\mathrm{P} / \mathrm{S}}\right.$, gram per gram) of the high isobutanol producer (JCL260), high isobutanol-tolerant (SA481), and parental (JCL16) strains cultured at $30^{\circ} \mathrm{C}$ and JCL260 at $37^{\circ} \mathrm{C}$. The $\mu$ was calculated during the exponential growth phase. Error bars indicate the difference between replicate cultures

tion was higher at $37^{\circ} \mathrm{C}$ (Fig. 2e), reaching a maximum concentration of $15.8 \pm 1.6 \mathrm{~g} / \mathrm{L}$ at $10.5 \mathrm{~h}$. Initially, it was hypothesized that the lower isobutanol production at $37^{\circ} \mathrm{C}$ was due to the poor quality of heterologous protein expression. To test this hypothesis, activities of four (AlsS, IlvD, KivD, and AdhA) enzymes involved in the biosynthetic isobutanol pathway were determined in bioreactor cultures performed at $30^{\circ} \mathrm{C}$ and $37^{\circ} \mathrm{C}$ (Fig. 6). Isobutanol, growth, and glucose time profile are shown in Fig. 6a, b, and in concordance with the results of Fig. 2a, maximum isobutanol concentration reached at $30^{\circ} \mathrm{C}$ was twofold higher than at $37^{\circ} \mathrm{C}$. Enzyme activities of AlsS, IlvD, and KivD were roughly similar in both $30^{\circ} \mathrm{C}$ and $37^{\circ} \mathrm{C}$ cultures (Fig. 6c-e). However, the AdhA activity (Fig. $6 \mathrm{f}$ ) in the $37^{\circ} \mathrm{C}$ culture was significantly lower than that in the $30^{\circ} \mathrm{C}$ culture from $17 \mathrm{~h}$ to the end of cultures, suggesting that this step may contribute to the difference between the two temperatures.

Kinetic and stoichiometric comparison of the strains

The specific growth rate $(\mu)$, volumetric productivity, and isobutanol yield on glucose were determined (Fig. 7). The specific growth rate for JCL260 was similar to the parental strain (JCL16) and was 5\% lower for SA480. As expected, the specific growth rate for JCL260 at $37^{\circ} \mathrm{C}$ was higher (around $26 \%$ ) than at $30^{\circ} \mathrm{C}$. In agreement, the acetate production was higher at $37^{\circ} \mathrm{C}$ than at $30^{\circ} \mathrm{C}$ because the acetate production rate is directly related to the specific growth rate (Eiteman and Altman 2006). The volumetric productivity of JCL260 at $30^{\circ} \mathrm{C}$ was $0.7 \mathrm{gL}^{-1} \mathrm{~h}^{-1}, 93 \%$ higher than the productivity of Clostridium beijerinckii BA101 for 1-butanol production estimated from data reported by Ezeji et al. (2003) using fermentation cultures with similar feeding and in situ product removal strategies (gas stripping integrated with fermentation process). In contrast, the volumetric productivity for JCL16 and the isobutanol-tolerant strain (SA481) was lower than JCL260. The maximum isobutanol yield on glucose (determined at the end of fermentation) for JCL2 60 cultivated at $30^{\circ} \mathrm{C}$ was $0.29 \pm 0.003 \mathrm{~g} / \mathrm{g}$, which is $68 \%$ of the theoretical maximum. A lower isobutanol yield on glucose was obtained for JCL260 at $37^{\circ} \mathrm{C}$ and for SA481.

\section{Discussion}

Batch fermentations were integrated with gas stripping to evaluate the isobutanol production of the highproducing (JCL260), high isobutanol-tolerant (SA481), and parental (JCL16) strains. For the first time, we were able to produce more than $50 \mathrm{~g} / \mathrm{L}$ of isobutanol in $72 \mathrm{~h}$. We found that with in situ product removal, E. coli was able to surpass the $22 \mathrm{~g} / \mathrm{L}$ produced in flask culture (Atsumi et al. 2008b).

Although SA481 has shown superior isobutanol tolerance to JCL260 (Atsumi et al. 2010b), it was not reflected in the final titer of isobutanol obtained in the integrated process. These results suggest that under these culture conditions, isobutanol production was not limited by growth or the product toxicity during growth phase. Atsumi et al. (2010b) found that isobutanol production, cell growth, and glucose consumption rate of SA481 tested in flask cultures were similar to those of JCL260 and that improved tolerance of SA481 did not increase the final titer. In this study, glucose consumption of SA481 was lower than that of JCL260; consequently, isobutanol production rate was also lower (Figs. 2a and 3). Cell growth of SA481 stopped around $22 \mathrm{~h}$, reaching practically the same cellular concentration as JCL260. At this time, isobutanol concentration in the broth was around $7 \mathrm{~g} / \mathrm{L}$ and cells did not grow even though there was no apparent nutrient limitation.

On the other hand, temperature should be an important factor in isobutanol production since the final titer at $37^{\circ} \mathrm{C}$ was $53 \%$ lower than at $30^{\circ} \mathrm{C}$. The observed difference might be caused by a lower Adh activity at $37^{\circ} \mathrm{C}$ toward the end of the culture (Fig. 6e) In addition, it has been reported that a shift-up in growth temperature decreases the proportion of unsaturated fatty acids in the membrane (Balamurugan 2010; Casadei et al. 2002; Ingram and Buttke 1984). Such changes in membrane composition may determine the tolerance level of cells to a particular stress. For example, Ingram and Buttke (1984) observed that alcohol tolerance of Zymomonas mobilis reduces with increasing growth temperatures. If such behavior will be the same for E. coli, poor isobutanol production at $37^{\circ} \mathrm{C}$ could be justified by a reduced alcohol tolerance compared with $30^{\circ} \mathrm{C}$. 
Brynildsen and Liao (2009) reported that $8 \mathrm{~g} / \mathrm{L}(1 \%)$ of isobutanol caused a growth arrest in $E$. coli, but even a lower concentration of solvent $(0.8 \%, v / v$, or $6.4 \mathrm{~g} / \mathrm{L}$ of $n$ butanol) caused a $50 \%$ growth decrease, disruption in respiratory efficiency, increased permeability of the cell wall, and oxidative stress response on E. coli (Rutherford et al. 2010). In this work, cell growth of JCL260 and JCL16 stopped around $10 \mathrm{~h}$ (when isobutanol concentration in the broth was roughly $7 \mathrm{~g} / \mathrm{L}$ ) and cells did not grow even after feeding. Such a phenomenon might be attributed to solvent toxicity because isobutanol concentration at $10 \mathrm{~h}$ was similar to those tested by Brynildsen and Liao (2009) and Atsumi et al. (2010b).

Even though the present work is not a complete optimization study, the results show that a very simple strategy (gas stripping) significantly improved the effective titer of isobutanol. Gas stripping avoids energy-intensive distillation and appears to be an effective method for product separation.

Acknowledgment This work was supported in part by UC MEXUS-CONACYT Postdoctoral fellowship program under the guidelines of the 2009-2010 UC MEXUS-CONACYT Call (I0101/ 120/07 MOD. ORD.-50-07).

Open Access This article is distributed under the terms of the Creative Commons Attribution Noncommercial License which permits any noncommercial use, distribution, and reproduction in any medium, provided the original author(s) and source are credited.

\section{References}

Alper H, Moxley J, Nevoigt E, Fink GR, Stephanopoulos G (2006) Engineering yeast transcription machinery for improved ethanol tolerance and production. Science 314:1565-1568

Atsumi S, Cann AF, Connor MR, Shen CR, Smith KM, Brynildsen MP, Chou KJ, Hanai T, Liao JC (2008a) Metabolic engineering of Escherichia coli for 1-butanol production. Metab Eng 10:305-311

Atsumi S, Hanai T, Liao JC (2008b) Non-fermentative pathways for synthesis of branched-chain higher alcohols as biofuels. Nature 451:86-89

Atsumi S, Higashide W, Liao JC (2009) Direct photosynthetic recycling carbon dioxide to isobutyraldehyde. Nat Biotechnol 27:1177-1180

Atsumi S, Tung-Yun W, Eckl EM, Hawkins SD, Buelter T, Liao JC (2010a) Engineering the isobutanol biosynthetic pathway in Escherichia coli by comparison of three aldehyde reductase/ alcohol dehydrogenase genes. Appl Microbiol Biotechnol 85:651-657

Atsumi S, Wu TY, Machado IMP, Huang WC, Chen PY, Pellegrini M, Liao JC (2010b) Evolution, genomic analysis, and reconstruction of isobutanol tolerance in Escherichia coli. Mol Syst Biol 6:449. doi: $10.1038 / \mathrm{msb} .2010 .98$

Balamurugan S (2010) Growth temperature associated protein expression and membrane fatty acid composition profiles of Salmonella enterica serovar typhimurium. J Basic Microbiol 50:507-518

Brynildsen MP, Liao JC (2009) An integrated network approach identifies the isobutanol response network of Escherichia coli. Mol Syst Biol 5:277
Cann AF, Liao JC (2008) Production of 2-methyl-1-butanol in engineered Escherichia coli. Appl Microbiol Biotechnol 81:89-98

Casadei MA, Manas P, Niven G, Needs E, Mackey BM (2002) Role of membrane fluidity in pressure resistance of Escherichia coli NCTC 8184. App Environ Microbiol 68:5965-5972

Chang D, Shin S, Rhee JS, Pan JG (1999) Acetate metabolism in a pta mutant of Escherichia coli W3110: importance of maintaining acetyl coenzyme A flux for growth and survival. J Bacteriol 181:6656-6663

Clomburg JM, Gonzalez R (2010) Biofuel production in Escherichia coli: the role of metabolic engineering and synthetic biology. Appl Microbiol Biotechnol 86:419-434

Connor MR, Liao JC (2008) Engineering of an Escherichia coli strain for the production of 3-methyl-1-butanol. Appl Environ Microbiol 74:5769-5775

Dellomonaco C, Fava F, Gonzalez R (2010) The path to next generation biofuels: successes and challenges in the era of synthetic biology. Microbial Cell Factories 9:3

Eiteman MA, Altman E (2006) Overcoming acetate in Escherichia coli recombinant protein fermentations. Trends Biotechnol 24:530-536

Ezeji TC, Qureshi N, Blaschek HP (2003) Production of acetone, butanol and ethanol by Clostridium beijerinckii BA101 and in situ recovery by gas stripping. World J Microbiol Biotechnol 19:595-603

Farmer WR, Liao JC (1997) Reduction aerobic acetate production Escherichia coli. Appl Environ Microbiol 63:3205-3210

Garcia AI, Garcia LA, Diaz M (1994) Fusel alcohols production in beer fermentation processes. Process Biochem 29:303-309

Gonzalez R, Tao H, Purvis JE, York SW, Shanmugam KT, Ingram LO (2003) Gene array-based identification of changes that contribute to ethanol tolerance in ethanologenic Escherichia coli: comparison of KO11 (parent) to LY01 (resistant mutant). Biotechnol Prog 19:612-623

Groot WJ, van der Lans RGJM, Luyben KChAM (1992) Technologies for butanol recovery integrated with fermentations. Process Biochem 27:61-75

Ingram LO, Buttke TM (1984) Effects of alcohols on microorganisms. Adv Microb Physiol 25:253-300

Inokuma K, Liao JC, Okamoto M, Hanai T (2010) Improvement of isopropanol production by metabolically engineered Escherichia coli using gas stripping. J Biosci Bioeng 110:696-701. doi:10.1016/j.jbiosc.2010.07.010

Jarboe LR, Zhang X, Wang X, Moore JC, Shanmugam KT, Ingram LO (2010) Metabolic engineering for production of biorenewable fuels and chemicals: contributions of biosynthetic biology. J Biomed Biotechnol 2010:761042. doi:10.1155/2010/761042

Lee SY, Park JH, Jang SH, Nielsen LK, Kim J, Jung KS (2008) Fermentative butanol production by Clostridia. Biotechnol Bioeng 101:209-228

Miller EN, Ingram LO (2007) Combined effect of betaine and trehalose on osmotic tolerance of Escherichia coli in mineral salts medium. Biotechnol Lett 29:213-217

Nielsen DR, Prather KJ (2009) In situ product recovery of $n$-butanol using polymeric resins. Biotechnol Bioeng 102:811-821

Peralta-Yahya PP, Keasling JD (2010) Advanced biofuel production in microbes. Biotechnol J 5:147-162

Phue JN, Lee SJ, Kaufman JB, Negrete A, Shiloach J (2010) Acetate accumulation through alternative metabolic pathways in ackApta- poxB- triple mutant in E. coli B (BL21). Biotechnol Lett 32:1897-1903

Qureshi N, Blaschek HP (1999) Production of acetone butanol ethanol (ABE) by a hyper-producing mutant strain of Clostridium beijerinckii BA101 and recovery by pervaporation. Biotechnol Prog 15:594-602

Qureshi N, Hughes S, Maddox IS, Cotta MA (2005) Energyefficient recovery of butanol from model solutions and 
fermentation broth by adsorption. Bioprocess Biosyst Eng 27:215-222

Roffler SR, Blanch HW, Wilke CR (1987) In-situ recovery of butanol during fermentation. Bioprocess Eng 2:1-12

Rutherford BJ, Dahl RH, Price RE, Szmidt HL, Benke PI, Mukhopadhyay A, Keasling JD (2010) Functional genomic study of exogenous $n$-butanol stress in Escherichia coli. Appl Environ Microbiol 76:1935-1945

Shen CR, Liao JC (2008) Metabolic engineering of Escherichia coli for 1-butanol and 1-propanol production via the keto-acid pathways. Metab Eng 10:312-320

Smith KM, Cho KM, Liao JC (2010) Engineering Corynebacterium glutamicum for isobutanol production. Appl Microbiol Biotechnol $87: 1045-1055$
Solomon BD (2010) Biofuels and sustainability. Ann NY Acad Sci 1185:119-134

Stephanopoulos G (2007) Challenges in engineering microbes for biofuels production. Science 315:801-804

Wolfe AJ (2005) The acetate switch. Microbiol Mol Biol Rev 69:1250

Wong MS, Wu S, Causey TB, Bennett GN, San KY (2008) Reduction of acetate accumulation in Escherichia coli cultures for increased recombinant protein production. Metab Eng 10:97108

Yomano LP, York SW, Ingram LO (1998) Isolation and characterization of ethanol-tolerant mutants of Escherichia coli KO11 for fuel ethanol production. J Ind Microbiol Biotechnol 20:132$138 \mathrm{~S}$ 